\title{
Outcome of laparoscopic Nissen fundoplication in patients with disordered preoperative peristalsis
}

\author{
R J Baigrie, D I Watson, J C Myers, G G Jamieson
}

\begin{abstract}
Background-A $360^{\circ}$ or Nissen fundoplication remains controversial in patients with disordered peristalsis, some surgeons preferring a partial wrap to minimise postoperative dysphagia.

Aim-To evaluate symptoms and manometric outcome in patients with disordered peristalsis after Nissen fundoplication.

Patients-In an initial series of 345 patients studied prospectively, 31 patients who had undergone a Nissen fundoplication had disordered peristalsis. Using preoperative manometry, patients were classified as: equivocal primary peristalsis (eight patients); abnormal primary peristalsis (four patients); abnormal maximal contraction pressure (13 patients); abnormal primary peristalsis and maximal contraction pressure (six patients).

Methods-Postoperatively, patients underwent a barium meal, oesophageal manometry and standardised clinical review by a blinded scientific officer.

Results-Twenty eight $(90 \%)$ patients had satisfaction scores of at least 8 out of a maximum of 10 and all would undergo surgery again. Whereas $15(48 \%)$ patients had dysphagia scores greater than $4 / 10$ preoperatively, only two $(6 \%)$ had these scores at one year. Improved peristalsis was seen in $78 \%$ of postoperative manometric studies, and mean preoperative lower oesophageal sphincter pressure increased from 6.6 (range 0-21) $\mathrm{mm} \mathrm{Hg}$ to 19 (4-50) $\mathrm{mm}$ Hg.
\end{abstract}

Conclusions-These results are similar to the overall group of 345 patients and suggest that disordered peristalsis, and possibly even absent peristalsis, is not a contraindication to Nissen fundoplication as performed in these patients.

(Gut 1997; 40: 381-385)

University Department of Surgery, Royal Adelaide

Hospital,

Adelaide,

South Australia 5000

R J Baigrie

D I Watson

J C Myers

G G Jamieson

Correspondence to:

Mr Robert J Baigrie,

Nuffield Department of

Surgery,

Surgery,

John Radcliffe Hospital,

Accepted for publication

31 October 1996
Keywords: laparoscopic, Nissen, fundoplication, peristalsis, motility, manometry.

Antireflux surgery is a well established treatment for reflux disease and represents the only means of cure. The laparoscopic approach has greatly lessened the procedure's morbidity, most of which is wound related and its efficacy is now well established. ${ }^{12}$ The use of a $360^{\circ}$ wrap remains controversial in patients with disordered peristalsis, some surgeons preferring a partial or modified wrap to avoid postoperative dysphagia. ${ }^{3-6}$ Dysphagia occurs in most patients immediately after fundoplication and is present at three months in $10-40 \% .^{78}$ By one year this has reduced to less than $10 \% .^{17}$ This study examines the incidence of symptoms, including dysphagia, and patient satisfaction after laparoscopic fundoplication in patients with disordered peristalsis.

\section{Methods}

Since the introduction of laproscopic Nissen fundoplication in this unit in 1990, all patients have been studied prospectively.

\section{Manometry}

The manometry was carried out in standard fashion after an overnight fast, with an eight lumen water perfusion catheter, incorporating a Dent sleeve sensor (Dent Sleeve, Adelaide, SA, Australia) with signals recorded on a polygraph chart recorder (model 7D, Grass Instrument Company, MA, USA). The manometric tube had side holes located at 5 $\mathrm{cm}$ intervals above the Dent sleeve to enable determination of motility responses of the oesophageal body. The lower oesophageal sphincter was located by the station pull through technique and the sleeve was positioned at the lower oesophageal sphincter. Each lumen of the catheter was connected in series with a pressure transducer (Statham P231D, Gould Inc, Oxnard, CA, USA) and was constantly perfused with degassed distilled water at $0.5 \mathrm{ml} / \mathrm{min}$ by a low compliance pneumohydraulic pump (Arndorfer Medical Specialties, Greendale, WI, USA).

After introduction of the catheter nasally and an adaption period, a five minute resting lower oesophageal sphincter pressure was measured during a relatively stable period, free of interference by dry swallows. Oesophageal sphincter measurements were taken every 15 seconds at the end of expiration, the pressure calculated in relation to intragastric pressure, and a median sphincter pressure determined.

After determining baseline pressures, the amplitude and success of primary peristalsis, and residual relaxation (nadir) pressure of the lower oesophageal sphincter were measured during at least 10 swallows of $5 \mathrm{ml}$ water boluses at 30 second intervals. Oesophageal body contraction pressures were calculated in the same respiration phase with reference to absolute zero for successful wet swallows and the mean was determined. Peristaltic success was defined as a wet swallow propagating the oesophageal body by primary peristalsis, and 
peristaltic failure as a failure to produce a contraction amplitude $\geqslant 10 \mathrm{~mm} \mathrm{Hg}$ at two or more recording sites.

Manometric data were analysed for the occurrence of failed primary peristalsis or hypotensive (sometimes called feeble) peristalsis in the distal oesophagus. Abnormal primary peristalsis was defined as less than $50 \%$ of water swallows progressing through the whole oesophagus. A value between $50 \%$ and $70 \%$ was regarded as equivocal primary peristalsis. A mean contraction amplitude $<25$ $\mathrm{mm} \mathrm{Hg}$ in the distal oesophagus was regarded as abnormal.

\section{Patients}

These criteria, which have been described previously, ${ }^{910}$ identified 31 patients with disordered peristalsis who underwent a laparoscopic Nissen fundoplication and who could be categorised in four groups.

Equivocal primary peristalsis-primary peristalsis $>50 \%$ and $<70 \%$ of swallows propagated, maximum contraction pressure $>25$ $\mathrm{mm} \mathrm{Hg}$.

Abnormal primary peristalsis-primary peristalsis $<50 \%$ of swallows propagated, maximum contraction pressure $>25 \mathrm{~mm} \mathrm{Hg}$.

Abnormal maximal contraction pressureprimary peristalsis $>50 \%$ of swallows propagated, maximum contraction pressure $<25$ $\mathrm{mm} \mathrm{Hg}$.

Abnormal primary peristalsis and maximal contraction pressure-primary peristalsis $<50 \%$ of swallows propagated and maximum contraction pressure $<25 \mathrm{~mm} \mathrm{Hg}$.

\section{Surgery}

The operative technique has been described in detail previously ${ }^{2}$ and entails the laparoscopic construction of a short $(2-3 \mathrm{~cm})$ loose $360^{\circ}$ fundoplication, calibrated over a 52FG bougie within the lumen of the oesophagus. Three or four interrupted prolene sutures were used to secure the fundoplication.

\section{Follow up}

Preoperative assessment and postoperative clinical follow up utilised a standardised questionnaire, administered by a scientific officer three, 12, and 24 months after surgery. Visual analogue scales were used to assess heartburn $(0=$ no heartburn, $10=$ severe heartburn), dysphagia ( $0=$ no dysphagia, $10=$ severe dysphagia), as well as patient satisfaction with the procedure $(0=$ completely dissatisfied, $10=$ completely satisfied). A dysphagia score $>3$ was regarded as troublesome dysphagia. The presence or absence of gas bloat, ability to burp and to relieve gastric distension, as well as the patient's willingness to undergo the same procedure again under similar preoperative circumstances, were also determined. Between three and four months after surgery, patients were encouraged to undergo further oesophageal manometry examination. Endoscopy was reserved for symptomatic patients with clinical indications.

\section{Results}

Eighteen male and 13 female patients with a $\stackrel{\mathbb{Q}}{\Omega}$ median age of 45 (range 33-81) were studied. ڤ No patient has been lost to clinical follow up, $\overrightarrow{0}$ with $11(36 \%)$ patients having been followed up for more than two years, $19(61 \%)$ for $\vec{\omega}$ 12 months, and one (3\%) for six months. Postoperative manometry has been performed on $17(55 \%)$ patients.

Equivocal primary peristalsis $(n=8)$

At one to two years six patients had satisfaction scores of at least 9 (Table), and would choose $\vec{z}$ to undergo the procedure again. Four patients had a preoperative dysphagia score $>3$, but by $\stackrel{\cap}{د}$ 12 months only one of these still had a score $\vec{\varphi}$ $>3$. One patient with a satisfaction score of $6 \stackrel{?}{v}$ developed abdominal pain two months after the operation and was found to have retroperitoneal fibrosis requiring ureterolysis. $\frac{\partial}{\partial}$ She would still choose to undergo the operation again. The last patient had a $\stackrel{2}{\perp}$ satisfaction score of zero with a reflux score of $\overrightarrow{\vec{A}}$ 10. Although it seems probable that the wrap $\frac{0}{3}$ has failed, the patient, who has serious psychiatric problems, was not prepared to be reinvestigated. No other patient was troubled $\stackrel{0}{0}$ by bloating or reflux at one year. Two patients underwent postoperative manometry, with a 3 rise in primary peristalsis in one patient and a fall in the other (Table and Fig 1).

Abnormal primary peristalsis $(n=4)$
All patients in this group had an excellent symptomatic outcome at 12 to 24 months, with of satisfaction scores of 9 or 10 and no reflux $\mathbb{O}$ (Table). All would undergo the operation again given similar preoperative circumstances. 우 Three of the four patients had a preoperative 0 dysphagia score $>3$, but no patient complained $\stackrel{D}{\mathbb{D}}$ of dysphagia, bloating, or reflux one year after $\stackrel{+}{+}$ the operation.

Postoperative manometry was available on $\frac{\vec{d}}{\vec{D}}$ two patients whose primary peristalsis had $\frac{P}{\mathbb{D}}$ recovered, in the first patient from $40 \% \stackrel{\square}{\square}$ preoperatively to $70 \%$, and in the second patient from $10 \%$ preoperatively to $100 \%$ ᄋ (Table and Fig 1).

Abnormal maximum contraction pressure $(n=13)$ Eleven patients 12 months after surgery and one at six months were virtually symptom free, with satisfaction scores of at least 8 (Table). All 12 would choose to undergo the operation again, and no patient had residual reflux or was troubled by bloating. Seven of the group had 
Preoperative and postoperative manometry data, and symptom scores for all 31 patients (the greater of the dysphagia scores (for liquids and solids) is recorded)

\begin{tabular}{|c|c|c|c|c|c|c|c|c|c|}
\hline \multirow[b]{2}{*}{ Patient group } & \multicolumn{2}{|l|}{$P P$} & \multicolumn{2}{|l|}{$M C P$} & \multirow{2}{*}{$\begin{array}{l}\text { LOS } \\
\text { Postop }\end{array}$} & \multirow{2}{*}{$\begin{array}{l}\text { Nadir } \\
\text { Postop }\end{array}$} & \multicolumn{2}{|c|}{ Dysphagia } & \multirow[b]{2}{*}{ Satisfaction } \\
\hline & Preop & Postop & Preop & Postop & & & Preop & Postop & \\
\hline $\begin{array}{l}\text { Equivocal PP only } \\
\quad(n=8)\end{array}$ & $\begin{array}{l}60 \\
60 \\
60 \\
60 \\
60 \\
60 \\
50 \\
50\end{array}$ & $\begin{array}{r}100 \\
40\end{array}$ & & & $\begin{array}{l}19 \\
32\end{array}$ & $\begin{array}{r}5 \\
13\end{array}$ & $\begin{array}{l}0 \\
5 \\
0 \\
0 \\
7 \\
4 \\
0 \\
5\end{array}$ & $\begin{array}{l}0 \\
8 \\
3 \\
0 \\
1 \\
0 \\
3 \\
0\end{array}$ & $\begin{array}{r}10 \\
6 \\
9 \\
10 \\
10 \\
10 \\
0 \\
10\end{array}$ \\
\hline $\begin{array}{l}\text { Abnormal PP only } \\
(n=4)\end{array}$ & $\begin{array}{l}40 \\
30 \\
30 \\
10\end{array}$ & $\begin{array}{r}70 \\
100\end{array}$ & & & $\begin{array}{l}26 \\
25\end{array}$ & $\begin{array}{r}3 \\
-2\end{array}$ & $\begin{array}{r}0 \\
10 \\
8 \\
5\end{array}$ & $\begin{array}{l}3 \\
0 \\
0 \\
3\end{array}$ & $\begin{array}{r}9 \\
9 \\
9 \\
10\end{array}$ \\
\hline $\begin{array}{l}\text { Abnormal MCP only } \\
(n=13)\end{array}$ & & & $\begin{array}{l}21 \\
20 \\
15 \\
22 \\
10 \\
19 \\
24 \\
19 \\
18 \\
22 \\
15 \\
20 \\
22\end{array}$ & $\begin{array}{l}23 \\
31 \\
12 \\
12 \\
23 \\
53 \\
71 \\
34 \\
11 \\
22 \\
58\end{array}$ & $\begin{array}{r}19 \\
9 \\
10 \\
11 \\
44 \\
20 \\
10 \\
16 \\
4 \\
5 \\
15\end{array}$ & $\begin{array}{l}19 \\
-4 \cdot 5 \\
7 \\
-2 \cdot 5 \\
30 \\
13 \\
8 \\
12 \\
-3 \cdot 5 \\
2 \\
6\end{array}$ & $\begin{array}{r}10 \\
6 \\
0 \\
3 \\
7 \\
0 \\
8 \\
2 \\
5 \\
6 \\
0 \\
4 \\
0\end{array}$ & $\begin{array}{l}0 \\
4 \\
0 \\
0 \\
0 \\
3 \\
2 \\
1 \\
2 \\
0 \\
2 \\
0 \\
0\end{array}$ & $\begin{array}{r}8 \\
8 \\
10 \\
10 \\
10 \\
10 \\
9 \\
9 \\
4 \\
10 \\
10 \\
10 \\
10\end{array}$ \\
\hline $\begin{array}{l}\text { Abnormal PP and MCP } \\
(n=6)\end{array}$ & $\begin{array}{r}40 \\
30 \\
0 \\
0 \\
0 \\
20\end{array}$ & $\begin{array}{r}100 \\
40\end{array}$ & $\begin{array}{r}21 \\
25 \\
10 \\
15 \\
0 \\
20\end{array}$ & $\begin{array}{r}60 \\
120\end{array}$ & $\begin{array}{l}50 \\
15\end{array}$ & $\begin{array}{r}18 \\
1\end{array}$ & $\begin{array}{r}10 \\
0 \\
0 \\
5 \\
0 \\
10\end{array}$ & $\begin{array}{l}0 \\
0 \\
0 \\
3 \\
3 \\
0\end{array}$ & $\begin{array}{l}10 \\
10 \\
10 \\
10 \\
10 \\
10\end{array}$ \\
\hline
\end{tabular}

$\mathrm{PP}=$ primary peristalsis; $\mathrm{MCP}=$ maximum contraction pressure in the distal oesophagus; $\mathrm{LOS}=$ lower oesophageal sphincter pressure; nadir=nadir pressure; Preop=preoperative; Postop=postoperative.

a preoperative dysphagia score $>3$, but by 12 months only one of these still had a score $>3$. Postoperative manometry was carried out on 11 patients in this group with seven patients showing a higher than preoperative value, three patients a lower value, and one remaining unchanged (Table and Fig 2).

One patient had a satisfaction score of 4 and would not choose to undergo the procedure again. She denied dysphagia or reflux symptoms but had become intolerant of a variety of foods and developed tremors and palpitations which she attributed to the operation. Her operation had entailed division of short gastric vessels and hiatal repair. A barium meal and repeat endoscopy nine months later disclosed normal postfundoplication appearances. Postoperative manometry and $\mathrm{pH}$ studies showed evidence of a

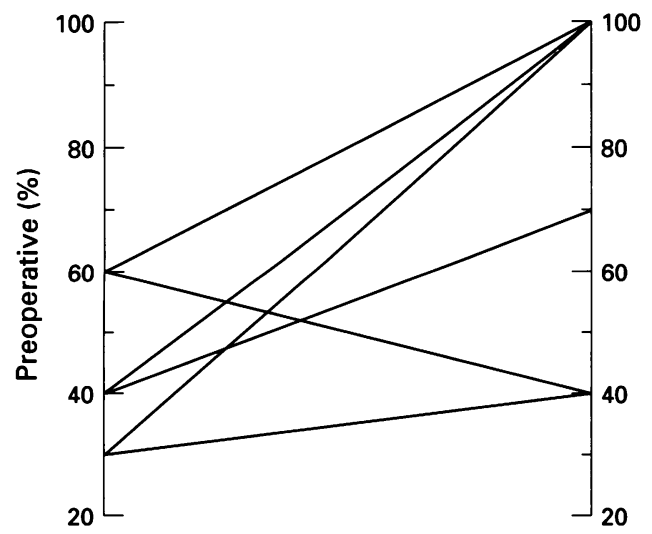

Figure 1: Primary peristalsis, measured preoperatively and at least three months postoperatively, in patients with equivocal abnormal preoperative primary peristalsis. very loose wrap, low contraction pressure, and equivocal reflux (Table). Postoperatively, oesophageal emptying was 53 seconds - within the normal range. The patient has been assessed by a cardiologist and a neurologist and her symptoms are thought to be related to anxiety.

\section{Abnormal primary peristalsis and maximum contraction pressure $(n=6)$}

This group included three patients with an adynamic oesophagus. Two year clinical follow up data were available for four patients, including those with an adynamic oesophagus. At three and 12 months, satisfaction scores were all 10 , with no reflux. Three of the six

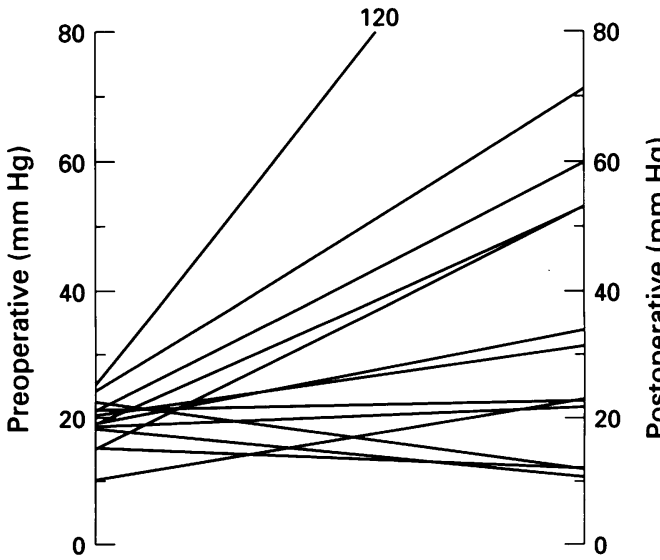

Figure 2: Maximum contraction pressures in the distal oesophagus, measured preoperatively and at least three months postoperatively, in patients with abnormal preoperative maximum contraction pressures. 
patients had a preoperative dysphagia score $>3$, but 12 months after the operation no patient complained of dysphagia, bloating or reflux. Postoperative manometry in two patients showed an improvement in both primary peristalsis and contraction amplitudes (Table and Figs 1 and 2). The three patients with an adynamic oesophagus declined postoperative manometry.

Analysis of all 31 patients showed median postoperative values of 16 (range 4-50) $\mathrm{mm}$ $\mathrm{Hg}$ for basal lower oesophageal sphincter pressure, and 6 (range -4.5 to 30 ) $\mathrm{mm} \mathrm{Hg}$ for nadir lower oesophageal sphincter pressure. Twenty eight $(90 \%)$ patients had satisfaction scores of at least 8 and all would undergo surgery again. Seventeen (54\%) patients had dysphagia scores of $>3$ preoperatively but only two $(6 \%)$ patients had persistence of this symptom at one year.

\section{Discussion}

This study presents the first prospective data of patients with disordered peristalsis undergoing laparoscopic fundoplication. Even in the era of open fundoplication, there was a paucity of prospective data and most published work was retrospective. Motility disturbances associated with gastro-oesophageal reflux disease were originally described by Olsen and Schlegel ${ }^{11}$ and impaired volume clearance was suggested by Stanciu and Bennett. ${ }^{12}$ Kahrilas et al ${ }^{13}$ defined "peristaltic dysfunction" as either failed propagated peristalsis, or peristaltic sequences with feeble contractions. They suggested that between $25 \%$ and $50 \%$ of patients with peptic oesophagitis have peristaltic dysfunction. Although our experience suggests a lower prevalence, the true incidence is probably masked by differences in study population and manometric selection criteria.

The surgeons were not blinded to the preoperative manometric findings, but the operation aimed at creating a short, loose fundoplication was carried out in a standard fashion for each patient. The fundoplication was always done with a 52 French gauge bougie in the oesophagus to ensure the looseness of the wrap, and no other manoeuvres were added in any patient to ensure a particularly loose wrap. A subgroup of patients did have short gastric vessel division within the context of a prospective randomised trial, rather than to try and achieve a particularly loose wrap. The results of this trial have shown division of these vessels make no difference to symptoms or manometric outcome. ${ }^{13 a}$

Detection of a severe motility disturbance in patients referred for anti-reflux sugery is considered mandatory by most surgeons. There is a belief that a total fundoplication will be followed by obstructive symptoms. Recently de Meester's group reported successful outcomes from open Nissen fundoplications in over 50 patients with mild non-specific motility disorders. ${ }^{14}$ Although none of their patients had postoperative manometry, symptom outcome was excellent. However, their patients all had considerably milder disorders of peristalsis than the patients in this study, and their manometric selection criteria for a Nissen fundoplication would have excluded almost all our patients with disordered primary peristalsis from undergoing this operation.

Evidence has been produced suggesting that oesophageal motor impairments are not reversible after surgery, ${ }^{15-18}$ although some recent data indicated that a substantialo improvement can occur in some cases. ${ }^{919}$ Our을. study had a high rate of postoperative $\frac{\text { ? }}{7}$ manometry $(56 \%)$ and there was an $\mathbb{D}$ improvement in the manometry findings of $12 \mathrm{\omega}$ patients, a slight deterioration in three, and no $\vec{\circ}$ change in two. Whereas these data, combinedwith the low level of postoperative dysphagia, $\vec{\omega}$ suggest improved motility after surgery, theo few patients preclude any firm conclusion.

The data presented suggest that disorderedo peristalsis (excluding achalasia) is not $a^{\omega \omega}$ contraindication for a $360^{\circ}$ loose laparoscopic $\infty$ fundoplication, with the incidence of dys-o phagia being improved by surgery. Pre- operative dysphagia is increasingly being 3 recognised as a common symptom in gastro-⿳亠丷厂 oesophageal reflux disease ${ }^{20}$ with $30-40 \%$ of 5 patients in our overall experience reporting thise symptom (unpublished data). The 54\%. incidence of preoperative dysphagia in ouro patients reflects their preoperative peristaltic dysfunction but this fell to $6 \%$ one year after operation. Two patients had an imperfect clinical outcome, but neither have dysphagia $\stackrel{\curvearrowright}{\propto}$ as a significant symptom. Overall patient $\overrightarrow{\vec{\rho}}$ satisfaction in this study group is similar to the 3 $91 \%$ satisfaction score seen in a series of 345 굴 patients who have undergone laparoscopic fundoplication in this unit and who have alsoo been subject to prospective analysis.

Our findings suggest that a $360^{\circ}$ fun- -3 doplication performed over a large bougie, either with or without division of short gastric 3 vessels, is appropriate treatment for gastro-o oesophageal reflux even when the patient has disordered oesophageal peristalsis.

We are most grateful to Miss Tanya Ellis for her help in collating the data.

1 Weerts JM, Dallemagne B, Hamoir E, et al. Laparoscopic $\mathbb{D}$ Nissen fundoplication: detailed analysis of 132 patients. Surg Laparosc Endosc 1993; 3: 359-64.

2 Jamieson GG, Watson DI, Britten-Jones R, Mitchell PC, $\bar{O}$ Anvari M. Laparoscopic Nissen fundoplication. Ann Surg( 1994; 220: 137-45.

3 Negre JB. Post-fundoplication symptoms; do they restrict $\overparen{\mathbb{Q}}$ the success of the Nissen fundoplication? Ann Surg 1983; 응 198: 698-700.

4 Pope CE. Esophageal motility - who needs it? Gastro-

enterology 1978; 74: 1088-94.
5 Fuchs K-H, Heimbucher J, Freys SM, Thiede A을 Management of gastro-esophageal reflux disease 1995. Tailored concept of anti-reflux operations. Diseases of the Tailored concept of anti-reflux operations. Diseases of the Esophagus 1994; 7: 250-4.

6 DeMeester TR, Stein HJ. Minimising the side-effects of anti-reflux surgery. World $\mathcal{F}$ Surg 1992; 16: 335-6.

7 Watson DI, Jamieson GG, Devitt PG, Mathew G, BrittenJones R, Game PA, Williams RS. Changing strategies in the performance of laparoscopic Nissen fundoplication as a result of experience with 230 operations. Surg Endosc 1995; 9: 961-6.

8 De Meester TR. Surgical management of gastroesophageal reflux. In: Castell DO, Wu WC, Ott DJ, eds. Gastroesophageal reflux disease. Pathogenesis, diagnosis, therapy. New York: Futura, 1985: 243-80. 
9 Kahrilas PJ, Dodds WJ, Hogan WJ, Kern M, Arndorfer RC, Reece A. Esophageal peristaltic dysfunction in peptic esophagitis. Gastroenterology 1986; 91: 897-904.

10 Lundell LR, Myers JJ, Jamieson GG. The influence of preoperative oesophageal motor function on long term outcome of anti-reflux surgery. Gullet 1993; 3: 50-5.

11 Olsen AM, Schlegel JF. Motility disturbances caused by esophagitis. $\mathcal{F}$ Thorac Cardiovasc Surg 1965; 50: $706-61$

12 Stanciu C, Bennett JR. Oesophageal acid clearing: one factor in the production of reflux oesophagitis. Gut 1974; 15: 852-7.

13 Kahrilas PJ, Dodds WJ, Hogan WJ. Effect of peristaltic dysfunction on esophageal volume clearance. Gastroenterology 1988; 94: 73-80.

13a Watson DI, Pike GK, Baigrie RJ, et al. A prospective double blind randomised trial of laparoscopic fundoplication with versus without division of short fundoplication with versus without division of short

14 Stin

Stein HJ, Bremner RM, Jamieson J, De Meester TR. Effect of Nissen fundoplication on esophageal motor function. Arch Surg 1992; 127: 788-91.
15 Russel COH, Pope CHE, Gannan RM, Allen FD, Velasco N, Hill LD. Does surgery correct esophageal motor dysfunction in gastroesophageal reflux? Ann Surg 1981; 194: 290-6.

16 Behar J, Sheahan DG, Biancani P, et al. Medical and surgical management of reflux oesophagitis, a 38-month report on a prospective clinical trial. $N$ Engl $\mathcal{F} M e d 1975$; report on a prospective clinical trial. NEngl f Med 1975;

17 Echardt VF. Does healing of esophagitis improve oesophageal motor function? Dig Dis Sci 1988; 33: $161-5$.

18 Katz PQ, Knuff TE, Benjamin SD, Castell DO. Abnormal esophageal pressures in reflux esophagitis: cause or effect? Am f Gastroenterol 1986; 81: 744-6.

19 Oritz Escandell A, Martinez de Haro LF, Parillo Paricio P, et al. Surgery improved defective oesophageal peristalsis in patients with gastro-oesophageal reflux. Br f Surg 1991; 78: $1095-7$.

20 Bremner RM, De Meester TR, Crookes PF, et al. The effect of symptoms and nonspecific motility abnormalities on outcomes of surgical therapy for gastroesophageal reflux disease. $\mathcal{F}$ Thorac Cardiovasc Surg 1994; 107: 1244-50. 